\title{
SOCIAL CONTACTS AND OCCUPATIONAL CHOICE
}

\author{
Samuel Bentolila, Claudio Michelacci and \\ Javier Suarez
}

CEMFI Working Paper No. 0406

March 2004

CEMFI

Casado del Alisal 5; 28014 Madrid

Tel. (34) 914290 551. Fax (34) 914291056

Internet: www.cemfi.es

The first author is also affiliated with CEPR and CESifo, the second and the third with CEPR. We would like to thank Harry Holzer for helping us locate the US data, and Manuel Arellano, Henry Farber, John Ham, Alan Manning, Andrea Ichino, Steve Pischke, Pedro Portugal, Mauro Sylos Labini, and Frank Vella for comments and suggestions. We are also grateful to seminar audiences at the European University Institute, the Humboldt University in Berlin, the London School of Economics, Universitat Autònoma de Barcelona, and at the Conference on "Advances in Economic Research" in Universidad de Navarra, Pamplona. We also wish to thank Cristina Barceló for help with the ECHP dataset. Financial support from the Spanish Ministerio de Ciencia y Tecnología through Project SEC2000-279 is gratefully acknowledged. 
CEMFI Working Paper 0406

March 2004

\title{
SOCIAL CONTACTS AND OCCUPATIONAL CHOICE
}

\begin{abstract}
Social contacts help workers to find jobs, but those jobs need not be in the occupations where workers are most productive. Hence social contacts can generate mismatch between a worker's occupational choice and his comparative productive advantage. Thus economies with dense social networks can exhibit apparently low labor force quality and, as a result, low returns to firms' investment and depressed aggregate productivity. We employ US and European data for the 1990's to test the key prediction that social contacts distort workers' occupational choices in a direction that reduces their apparent productivity. We find that the use of social contacts helps find jobs one to two months sooner but leads to individual wage discounts of $5 \%$ to $7 \%$ and produces negative externalities on aggregate productivity.
\end{abstract}

JEL Codes: J24, J41, 015

Keywords: Mismatch, search and social mobility

Samuel Bentolila

CEMFI

bentolila@cemfi.es
Claudio Michelacci

CEMFI

c.michelacci@cemfi.es
Javier Suarez

CEMFI

suarez@cemfi.es 


\section{Introduction}

Friends and relatives are often recognized as a useful source of information on jobs, and much research has emphasized the positive role of social contacts in helping people to find jobs. For instance, in a number of studies for the US surveyed by Montgomery (1991), the share of workers reporting to have found their jobs through friends or relatives ranges from $24 \%$ to $74 \%$, depending on the occupation and the locality of reference.

However, social contacts are usually acquired and maintained for other purposes and they typically help a worker to find a job only in specific occupations or segments of the labor market. ${ }^{1}$ Thus the availability of social contacts and the opportunity to find a job more easily may convince a worker to undertake a career in professions, sectors, or locations where his abilities are not fully exploited. In brief, social contacts may produce a mismatch between workers' comparative productive advantage and their occupational choices.

To analyze the aggregate implications of this mismatch, we assume that the labor market for each occupation is characterized by search frictions. Each worker has productive advantage in a given occupation while he may have contacts useful for finding a job in either the same or other occupations. Then some workers face a trade-off between choosing the occupation in which they would be most productive and using their contacts to find a job. The larger the worker's endowment of social contacts, the larger is the productive advantage needed to convince the worker to choose an occupation where his advantage is fully exploited.

In the equilibrium of this economy, workers tend to exploit too little of their productivity potential since they do not internalize the positive effects of the improvement in the average productivity of the labor force on vacancy creation and on firms' incentives to invest capital in those vacancies (provided that capital is complementary to workers' productivity). Interestingly, social contacts can be so distortionary that aggregate net

\footnotetext{
${ }^{1}$ Workers do not have contacts in every relevant occupation. Indeed, in one of the databases that we use in this paper, which includes workers in three large US cities (Atlanta, Boston, and Los Angeles) in the early $1990 \mathrm{~s}, 53 \%$ of the respondents state that they did not talk to relatives as a method of job search and $26 \%$ that they did not talk to friends.
} 
income may fall in response to an increase in the aggregate endowment of social contacts. In this context, subsidies to workers' occupational or spatial mobility or other policies that weaken the influence of family ties and neighbor networks on occupational choices would be welfare improving. Also, since workers find social contacts relatively more valuable when the labor market is sluggish and jobs are harder to find, the economy may get stuck in a trap in which some workers do not fully exploit their productivity potential because the economy is depressed, which in turn is due to the poor average productivity of the labor force that workers' occupational choices induce.

One key implication of the mismatch between workers' comparative productive advantage and their actual occupational choice is that, on average, jobs found through contacts are obtained more quickly but also pay lower wages, since at least some of them are filled by workers who sacrificed their productive advantage in order to get a job more easily. We test this prediction by using two datasets, one for the US and one for Europe. The US data come from the "Multi-City Study of Urban Inequality, 19921994" (see Bobo et al., 2000), a survey well suited for testing the model's key trade-off, since it contains detailed information about workers' job search methods. The data for the European Union come from the European Community Household Panel (ECHP) over 1994-1998. In both datasets we find evidence of a significant wage discount for jobs found through family-and-friends contacts, of the order of 5 to $7 \%$. Furthermore, the typical unemployment duration for workers who found a job through contacts is significantly lower than that for workers who found a job through other methods, which provides support for the claim that individuals may trade off an easier access to jobs with higher productivity and wages.

We are not the first to analyze the effects of finding a job through contacts on wages and unemployment duration. The individual benefits of social contacts in generating job offers and reducing unemployment duration is well documented by, among others, Holzer (1988) and Blau and Robins (1990). The effect on wages is empirically less clear. The literature has mostly focused on the effects of employee referrals, with mixed results. Granovetter (1974), Corcoran et al. (1980), Simon and Warner (1992) and Kugler 
(2003) found positive (albeit sometimes non-significant) wage premia for jobs found through referrals from current employees. Our paper focuses, instead, on the effects of the contacts provided by family and friends. ${ }^{2}$ Furthermore, we focus on relatively young workers at their first permanent job in order to better isolate the key trade-off of the paper — that should typically occur at an early stage of the individual's working lifeand to disentangle the effects of social contacts from those of professional contacts - that may well provide better job opportunities in a given occupation rather than distorting the workers' occupational choice. ${ }^{3}$

Several theoretical pieces emphasize that the use of contacts in the labor market is beneficial because they provide more information about the worker (Saloner, 1985, and Montgomery, 1991), because they allow a more effective sampling from a given wage distribution (Mortensen and Vishwanath, 1994, and Calvo-Armengol and Jackson, 2003, 2004), because they are a source of peer monitoring (Kugler, 2003), or because they provide a cheaper search channel (Holzer, 1988, and Santamaria-Garcia, 2003). In any of these ways, an increase in the worker's endowment of contacts amounts to a net improvement in his wage possibilities, so that these models predict that jobs found through contacts should pay higher wages. We are the first in emphasizing that workers may sacrifice their productive advantage to find a job more easily, thereby explaining why jobs found through social contacts exhibit a wage discount rather than a premium.

This paper relates to several other strands of the literature which have recently become very active. First, we contribute to the literature analyzing how social capital affects the functioning of the aggregate economy. ${ }^{4}$ Social contacts help the spreading of

\footnotetext{
${ }^{2}$ Simon and Warner (1992), for a sample of US scientists and engineers, Pistaferri (1999), for Italian data, and Pellizzari (2003), for a set of European countries, also find a wage discount associated with jobs found through family and friends.

${ }^{3}$ Some recent work has found specific groups of workers among which an increase in workers' endowment of contacts leads to higher-paying jobs — see Marmaros and Sacerdote (2002), who consider a sample of Dartmouth College seniors, and Munshi (2003), who deals with a sample of Mexican migrants to the US. These findings do not necessarily contradict our theory since, within the specific samples of workers which are analyzed, occupational choices are unlikely to be distorted by the considerations that we emphasize.

${ }^{4}$ See for example Knack and Keefer (1997) and Guiso et al. (2000).
} 
information and thus are a form of social capital in the sense of Coleman (1988). ${ }^{5}$ Our results point towards the importance of analyzing the various forms of social capital, since not all of them necessarily promote an efficient functioning of the economy.

Our analysis also suggests a novel interpretation for the high inter-generational persistence of segregation by skill and occupation, documented by Borjas (1995). The literature has generally attributed this phenomenon to the role of peer effects in the transmission of human capital. Our theory suggests instead that inter-generational occupational and spatial mobility may remain low not because of transmitted characteristics of workers' human capital but because workers seek to use their inherited social connections to find jobs more easily.

Finally, our findings may also be relevant for some recent strands of the growth literature that stress how social infrastructure affects capital-labor ratios and aggregate productivity, as for example Hall and Jones (1999). We identify social contacts as one possible reason why the average quality of the labor force and the return to firms' investments may remain low.

The rest of the paper is organized as follows. Section 2 describes the model. Section 3 analyzes the equilibrium of the model, its comparative statics, and its efficiency. Section 4 develops an extension where contacts may induce a low-productivity trap. Section 5 describes the data and the empirical results. Section 6 concludes.

\section{The model}

Consider a static economy with two occupations, $i=1,2$, for each of which there is a separate labor market. ${ }^{6}$ There is a continuum of measure two of risk-neutral workers who, for simplicity, derive no utility from leisure. Workers' long-term occupational choices consist of deciding where to search for a job. Creating a job requires that a firm opens an occupation-specific vacancy, which has a cost $k>0$, and that the vacancy is

\footnotetext{
${ }^{5}$ Indeed he states that "An important form of social capital is the potential for information that inheres in social relations (...). In this case relationships are valuable for the information they provide."

${ }^{6}$ The analysis can be trivially extended to cases with more than two occupations.
} 
filled by a suitable worker. Firms are expected profit maximizers and there is free entry.

The market for each occupation is subject to search frictions that we model à la Pissarides (2000). Specifically, the total number of jobs created in occupation $i=0,1$ is determined by a matching function $M\left(V_{i}, U_{i}\right)$, where $V_{i}$ denotes the number of vacancies opened for occupation $i$ and $U_{i}$ denotes the total efficiency units of search used by the workers who choose occupation $i$. As usual, this function is assumed to be homogeneous of degree one, increasing in both arguments, concave, continuously differentiable, and upper-bounded by $\min \left\{V_{i}, U_{i}\right\}$. Thus, one efficiency unit of search of any given worker yields a match with a firm with probability

$$
p\left(\theta_{i}\right) \equiv m\left(\theta_{i}, 1\right)=\frac{m\left(V_{i}, U_{i}\right)}{U_{i}},
$$

where $\theta_{i} \equiv V_{i} / U_{i}$ is the so-called level of tightness in the market for occupation $i$. Clearly, $p\left(\theta_{i}\right)$ is increasing in $\theta_{i}$.

When a match is formed, the match surplus is split by using a Generalized Nash Bargaining Solution where the worker's and the firm's bargaining powers are $\beta$ and $1-\beta$, respectively. As the outside options of both the firm (leaving the vacancy unfilled) and the worker (remaining unemployed) are worth zero at that point, each employed worker's wage is equal to a fraction $\beta$ of his output in the job.

Workers are heterogeneously endowed with occupation-specific productive advantage and social contacts. A worker produces $(1+a) y$ if he exploits his productive advantage and $y>k$ if he does not. Social contacts are useful for finding a job in a specific occupation. In particular, let normalize to one the efficiency units of search associated with the exclusive use of formal channels (newspaper ads, private or public employment agencies, internet search, etc.). Then we assume that the efficiency units of search usable for finding a job in an occupation where the worker has contacts are $1+\tilde{s}$, where $\tilde{s}$ measures the worker's endowment of contacts specific to that occupation. ${ }^{7}$

For simplicity, we assume that every worker has his productive advantage and his contacts in exactly one occupation, which may coincide. Specifically, we assume that

\footnotetext{
${ }^{7}$ We start by assuming that social contacts only help workers find jobs. In Section 4 we extend the model to allow for social contacts to yield some additional benefits to the workers who use them.
} 
the allocation of productive advantage across occupations is purely random - half of the workers have their productive advantage in each occupation - and each worker has a probability $\rho \in[0,1]$ of having his productive advantage and his contacts in the same occupation. So $\rho$ measures the extent to which productive advantage and contacts are aligned.

To show the influence of workers' endowment of contacts on the resolution of the conflict between exploiting productive advantage and using contacts when these are misaligned, we assume that a fraction $\mu$ of workers has a large endowment of contacts, $\tilde{s}=S>a$, while the remaining fraction $1-\mu$ has a small one, $\tilde{s}=s<a$.

\section{Equilibrium analysis}

Since the fundamentals of the market for each occupation are identical, we focus on symmetric equilibria and drop the occupation subscript $i$ in the remainder. In equilibrium, each market attracts one unit mass of workers and is characterized by a level of tightness $\theta$ and an identical composition of the labor force in terms of per capita productivity and efficiency units of search used. We start by solving for these equilibrium variables and then we derive the equilibrium values and the comparative statics of some empirically relevant variables, such as average wages and unemployment duration conditional on the channel whereby the workers find their job. The section concludes by discussing the efficiency of the equilibrium allocation. To help the reader through the analysis, Table 1 summarizes the main equilibrium outcomes of the model.

\subsection{Solving for equilibrium}

Clearly, a worker whose contacts and productive advantage are in the same occupation always chooses to search for a job in that occupation. Instead, a worker with social contacts in one occupation and productive advantage in another faces a trade-off that gets resolved in favor of productive advantage if and only if

$$
p(\theta) \beta(1+a) y \geq p(\theta)(1+\tilde{s}) \beta y
$$


which, as $s<a<S$, implies that the worker follows his productive advantage when his endowment of contacts is small, $\tilde{s}=s$, but not when it is large, $\tilde{s}=S$.

Given these choices, the total efficiency units of search in the market for each occupation are given by

$$
\begin{aligned}
U & =\mu \rho(1+S)+(1-\mu) \rho(1+s)+\mu(1-\rho)(1+S)+(1-\mu)(1-\rho) \\
& =\mu(1+S)+(1-\mu)(1+\rho s)
\end{aligned}
$$

which results from adding up the efficiency units of search used by the various types of workers in the market. Specifically, the first two terms in the first line correspond to the measures $\mu \rho$ and $(1-\mu) \rho$ of workers with endowments of contacts $\tilde{s}=S$ and $\tilde{s}=s$, respectively, whose contacts and productive advantage are in the same occupation. The third term corresponds to the measure $\mu(1-\rho)$ of workers with a large endowment of contacts, $\tilde{s}=S$, who resolve their conflict between contacts and productive advantage by sacrificing the latter. Lastly, the fourth term corresponds to the measure $(1-\mu)(1-\rho)$ of workers with a low endowment of contacts, $\tilde{s}=s$, who resolve the conflict in favor of their productive advantage.

The fraction of efficiency units of search in the market accounted for by workers with productive advantage (or high productivity workers) is given by

$$
\gamma=1-\frac{\mu(1-\rho)(1+S)}{\mu(1+S)+(1-\mu)(1+\rho s)}
$$

which we express as one minus the fraction of efficiency units of search accounted for by workers who fail to exploit their productive advantage. These are the mass $\mu(1-\rho)$ of workers with $\tilde{s}=S$ who face a conflict between contacts and productive advantage. Clearly $1-\gamma$ is a measure of the mismatch between workers' occupational choices and productive advantage. By (3), the degree of mismatch is increasing in $\mu$ and $S$, and decreasing in $\rho$ and $s$ (up to $s$ equal to $a$ ). Intuitively, mismatch falls with any parameter that increases the presence of workers who follow their productive advantage.

Since firms appropriate a fraction $1-\beta$ of the worker's output in the job, the expected profit from opening a vacancy in any of the occupations is equal to

$$
\Pi=q(\theta)(1-\beta)(1+\gamma a) y-k
$$


where $q(\theta) \equiv m(V, U) / V=p(\theta) / \theta$ is the probability of filling the vacancy, which is decreasing in the level of labor market tightness, $\theta$.

The creation of vacancies till the exhaustion of rents implies the free-entry condition $\Pi=0$, that is:

$$
q(\theta)(1-\beta)(1+\gamma a) y=k
$$

Assuming hereafter that $(1-\beta) y \geq k, \lim _{x \rightarrow 0} q(x)=1$, and $\lim _{x \rightarrow \infty} q(x)=0$, it follows that (5) has a (unique) interior solution. Clearly, (5) identifies a positive relationship between the expected value of a worker to the firm, $(1-\beta)(1+\gamma a) y$, and the level of labor market tightness, $\theta$. Intuitively, when the former increases, firms have greater incentives to create vacancies, so $\theta$ increases.

\subsection{Some derived statistics}

Let the binary variable $c$ indicate whether a worker has found a job using his contacts $(c=1)$ or not $(c=0)$. Correspondingly, let $\varphi_{1}$ and $\varphi_{0}$ denote the proportions of high productivity workers among those employed through formal channels and through contacts, respectively. To compute $\varphi_{1}$ note that the total number of jobs filled through contacts is given by the product of $p(\theta)$ and $\mu S+(1-\mu) \rho s$, which is the sum of two terms. The first corresponds to workers with $\tilde{s}=S$, whose measure is $\mu$, who always use their contacts to search for a job and actually find one through contacts with probability $p(\theta) S$. The second corresponds to workers with $\tilde{s}=s$, whose measure is $1-\mu$, who use their contacts only if this does not come into conflict with exploiting their productive advantage, that is, with probability $\rho$. For them contacts prove to be useful to find a job with probability $p(\theta) s$. Finally, remember that the only workers who fail to exploit their productive advantage are those with a conflict between using their large endowment of contacts, $\tilde{s}=S$, and exploiting their productive advantage. This reasoning yields the proportion:

$$
\varphi_{1}=1-\frac{\mu(1-\rho) S}{\mu S+(1-\mu) \rho s}=\frac{\mu \rho S+(1-\mu) \rho s}{\mu S+(1-\mu) \rho s} \in[0,1] .
$$


Now, since wages are equal to a fraction $\beta$ of each worker's output, the average wage paid in a job which is filled through social contacts is equal to

$$
E(w \mid c=1)=\beta\left(1+\varphi_{1} a\right) y
$$

By a similar reasoning, we can obtain that

$$
\varphi_{0}=1-\mu(1-\rho)<1
$$

which uses the fact that all the jobs filled through formal channels correspond to high productivity workers except when the matches involve workers with a high endowment of contacts in an occupation where they do not have their productive advantage. The average wage paid in a job which is filled through formal channels is then equal to

$$
E(w \mid c=0)=\beta\left(1+\varphi_{0} a\right) y
$$

From (6) and (7), it follows that

$$
E(w \mid c=1)-E(w \mid c=0)=-\beta\left(\varphi_{0}-\varphi_{1}\right) y
$$

is strictly negative since we have:

$$
\varphi_{0}-\varphi_{1}=\mu(1-\rho) \frac{(1-\mu)(S-\rho s)}{\mu S+(1-\mu) \rho s}>0 .
$$

Thus:

Proposition 1 Jobs found through social contacts pay on average a lower wage than jobs found through formal channels.

Intuitively, since contacts induce some workers to sacrifice their productive advantage, the pool of workers who found jobs through social contacts have lower average productivity. Note that the wage discount would disappear if all workers had few contacts $(\mu=0)$ or if contacts and productive advantage were never in conflict $(\rho=1)$, since in this case no worker would give up his productive advantage. 
Next, let us refer to the inverse of a worker's probability of finding a job as his unemployment duration, denoted by $d$. The average unemployment duration across workers who find a job through formal channels is

$$
E(d \mid c=0)=\frac{1}{p(\theta)}\left[\frac{\mu}{1+S}+\frac{(1-\mu) \rho}{1+s}+(1-\mu)(1-\rho)\right] .
$$

To understand this expression, note that it averages three unemployment durations proportional to $1 / p(\theta)$. For the fraction $\mu$ of jobs found through formal channels by workers with a large endowment of contacts, the proportionality factor is $1 /(1+S)$. For the fraction $(1-\mu) \rho$ of jobs found through formal channels by workers with no conflict between productive advantage and their small endowment of contacts, the factor is $1 /(1+s)$. Finally, for the fraction $(1-\mu)(1-\rho)$ of workers who exploit their productive advantage instead of using their small endowment of contacts, the factor is just 1.

By an analogous reasoning we can compute the average unemployment duration of workers who find a job through contacts. This is equal to

$$
E(d \mid c=1)=\frac{1}{p(\theta)}\left[\frac{1}{1+S} \frac{\mu S}{\mu S+(1-\mu) \rho s}+\frac{1}{1+s} \frac{(1-\mu) \rho s}{\mu S+(1-\mu) \rho s}\right] .
$$

In Appendix 1 we show that $E(d \mid c=1)-E(d \mid c=0)$ is negative, implying that:

Proposition 2 Workers who find their jobs through contacts exhibit a lower unemployment duration than workers who find their jobs through formal channels.

Since contacts help workers to find jobs, the unemployment spells of workers who find jobs through them is typically shorter than that of workers who find their jobs through formal channels. Propositions 1 and 2 together reflect in empirically measurable terms the key trade-off faced by some of the workers in their occupational choices: jobs found through contacts tend to be found more quickly but they tend to pay lower wages.

\subsection{Comparative statics}

The following result illustrates the impact on labor market tightness of mismatch due to the effect of social contacts on workers' occupational choices. According to (5), labor 
market tightness, $\theta$, is increasing in the probability that a firm matches with a high productivity worker, $\gamma$, which in turn is decreasing in the proportion of workers with a large endowment of contacts, $\mu$, and the prevalence of the conflict between productive advantage and contacts, $1-\rho$. Thus:

Proposition 3 An increase in the proportion of workers with a large endowment of contacts or in the prevalence of the conflict between productive advantage and contacts reduces workers' expected productivity, causing labor market tightness to fall.

Intuitively, the reduction in the number of workers who exploit their productive advantage decreases the expected value of a worker to the firms. But then, firms react by creating less vacancies, making labor market tightness fall down to the point where the free-entry condition (5) is restored.

Interestingly, Proposition 3 implies that the probabilities of finding a job of both the workers who use contacts, $(1+\tilde{s}) p(\theta)$, and those who do not, $p(\theta)$, are also decreasing in the proportion of workers with a large endowment of contacts, $\mu$, and in the prevalence of the conflict between productive advantage and contacts, $1-\rho$.

\subsection{Efficiency}

Since workers and firms are risk-neutral, we define social welfare $W$ as aggregate output net of vacancy creation costs. Formally,

$$
W=2[p(\theta)(1+\gamma a) y-k \theta] U
$$

where the factor 2 accounts for the existence of two occupations and $U$ denotes the total efficiency units of search used by workers in each occupation, as given by (2). Note that $W$ is a function of the two crucial equilibrium variables of the model: the proportion of employed workers who exploit their productive advantage, $\gamma$, given by (3), and the level of labor market tightness, $\theta$, given by (5).

By deriving with respect to $\theta$ and after using (5) to replace $q(\theta)(1+\gamma a) y$ by $\frac{1}{1-\beta} k \theta$, we get

$$
\frac{\partial W}{\partial \theta}=\frac{2 k[\beta-\eta(\theta)] U}{1-\beta}
$$


where $\eta(\theta) \equiv \frac{q(\theta)+\theta q^{\prime}(\theta)}{q(\theta)}$ is the elasticity of the matching function with respect to $U$. As the value of $\beta$ and $\eta(\theta)$ need not coincide, the above derivative is generally different from zero, which means that the equilibrium level of tightness is generally inefficient. This inefficiency is of the type first pointed out by Hosios (1990) and it is due to the conjunction of search frictions and bargaining in the labor market. ${ }^{8}$

We have observed that as the proportion of workers with a large endowment of contacts, $\mu$, increases, workers' expected productivity falls, since a greater number of workers sacrifice their productive advantage. Despite the fact that contacts may help workers find jobs more easily, the effect on productivity can be strong enough for aggregate net income to fall when $\mu$ increases. In this sense social contacts can be inefficient. To prove this result, consider the total derivative of $W$ with respect to $\mu$, which after using (10) reads as

$$
\frac{d W}{d \mu}=\frac{\partial W}{\partial \mu}+\frac{\partial W}{\partial \theta} \frac{d \theta}{d \mu}
$$

where

$$
\frac{\partial W}{\partial \mu}=2 \frac{1}{1-\beta} k \theta\left[\beta(S-\rho s)-\frac{a}{1+\gamma a} \frac{(1-\rho)(1+\rho s)(1+S)}{\mu(1+S)+(1-\mu)(1+\rho s)}\right],
$$

in which we have used (5) to replace $p(\theta)(1+\gamma a) y-k \theta$ by $\frac{\beta}{1-\beta} k \theta$. Note that for $S \rightarrow a$, $\mu \rightarrow 1$, and $\rho \rightarrow 0$, the term in brackets becomes $-(1-\beta) a$, so that $\partial W / \partial \mu$ is strictly negative. Hence, by continuity, $\partial W / \partial \mu$ is strictly negative in the proximity of such limiting case. On the other hand, Proposition 3 implies that $d \theta / d \mu<0$. But then (11) and (12) allow us to conclude that:

Proposition 4 An increase in the fraction of workers with a large endowment of contacts may lead to a reduction in aggregate net income.

More specifically, we can ensure that increasing the fraction of workers with a large endowment of contacts, $\mu$, leads to a reduction in social welfare when: (i) the economy

\footnotetext{
${ }^{8}$ The anticipated division of the surplus, that results from the bargaining between firms and workers, determines firms' incentive to create new vacancies. But opposite to Walrasian prices, the bargaining powers $\beta$ and $1-\beta$ do not adjust to reflect the marginal social value of a vacancy. When, for instance, workers are "too strong" $(\beta>\eta(\theta))$, firms appropriate too little surplus and so they create too few vacancies.
} 
is characterized by insufficient vacancy creation (that is, $\beta>\eta(\theta)$ so that $\partial W / \partial \theta>0$ ), (ii) the private gains from sacrificing productive advantage are small $(S \rightarrow a)$, and (iii) contacts produce substantial mismatch $(\mu \rightarrow 1$ and $\rho \rightarrow 0)$.

This inefficiency is due to an externality similar to that emphasized by Acemoglu (1996). In equilibrium workers tend to sacrifice their productive advantage beyond what is socially optimal because they do not internalize the adverse effect that a reduction in aggregate labor productivity has on vacancy creation (and on firm's investment had capital been endogenous). In a first-best allocation, an increase in the aggregate endowment of social contacts would necessarily lead to an increase in aggregate net income, since contacts would only facilitate jobfinding. But in the equilibrium of this economy, social contacts tend to cause an excessive mismatch between workers' occupational choices and their productive advantage, depressing aggregate activity.

\section{Low productivity traps}

Sometimes the decision to work in an occupation where the worker has social contacts may be affected by considerations other than wages and job finding probabilities. For example, some individuals may feel pressed to comply with social conventions or family traditions calling them to choose a particular profession. Other individuals may find that having an occupation related to those of their family and friends may help maintain or develop relationships which have some (typically, nonpecuniary) value, for instance, by guaranteeing them emotional or material support in bad times. In this section we introduce these additional values from using social contacts by assuming that choosing the occupation where the worker has his social contacts yields some nonpecuniary benefits $b$, which are independent of his employment status.

An important finding in this section is the possibility of multiple equilibria, some of which may involve inefficient occupational choices and labor market outcomes. A second important result is that, even when social contacts appear to have a small effect on the measurable probabilities of finding a job, they may significantly distort (due to the nonpecuniary benefits) workers' occupational choices and produce a large degree of 
mismatch in the labor market.

Clearly the addition of the nonpecuniary benefits $b$ does not alter the occupational choice of workers whose contacts and productive advantage are in the same occupation. However a worker who faces a conflict between the two will now exploit his productive advantage only if

$$
p(\theta) \beta(1+a) y \geq p(\theta)(1+\tilde{s}) \beta y+b,
$$

which, relative (1), incorporates the term $b$. Thus, with $s<a<S$, a worker with a large endowment of contacts continues sacrificing his productive advantage, while for a worker with a low endowment of contacts, there exists a critical value

$$
\hat{p}=\frac{b}{\beta(a-s) y}
$$

such that he exploits his productive advantage if $p(\theta)>\hat{p}$, uses his contacts if $p(\theta)<\hat{p}$, and is indifferent between the two alternatives if $p(\theta)=\hat{p}$. The critical value $\hat{p}$ can be translated into a critical value of labor market tightness, $\widehat{\theta}=p^{-1}(\hat{p})$, above (below) which the worker exploits (sacrifices) his productive advantage.

To analyze the equilibrium implications of these choices, let $\lambda$ denote the proportion of workers with a conflict between productive advantage and their small endowment of contacts who end up exploiting their productive advantage. Then, the piecewise linear schedule $\lambda(\theta)$ depicted in Figure 1 gives the values of $\lambda$ which are compatible with the various possible values of $\theta$.

In turn, the proportion of high productivity workers among employed workers is a strictly increasing function $\gamma(\lambda)$ of the variable $\lambda$. In particular, we have

$$
\gamma(\lambda)=\frac{\mu \rho(1+S)+(1-\mu) \rho(1+s)+(1-\mu)(1-\rho) \lambda}{\mu(1+S)+(1-\mu) \rho(1+s)+(1-\mu)(1-\rho)[(1-\lambda)(1+s)+\lambda]} .
$$

As in the baseline model, the proportion of high productivity workers among employed workers determines the expected value of a worker to a firm and, thus, the incentives for creating vacancies. Specifically, firms' free entry condition is now

$$
q(\theta)(1-\beta)[1+\gamma(\lambda) a] y=k,
$$




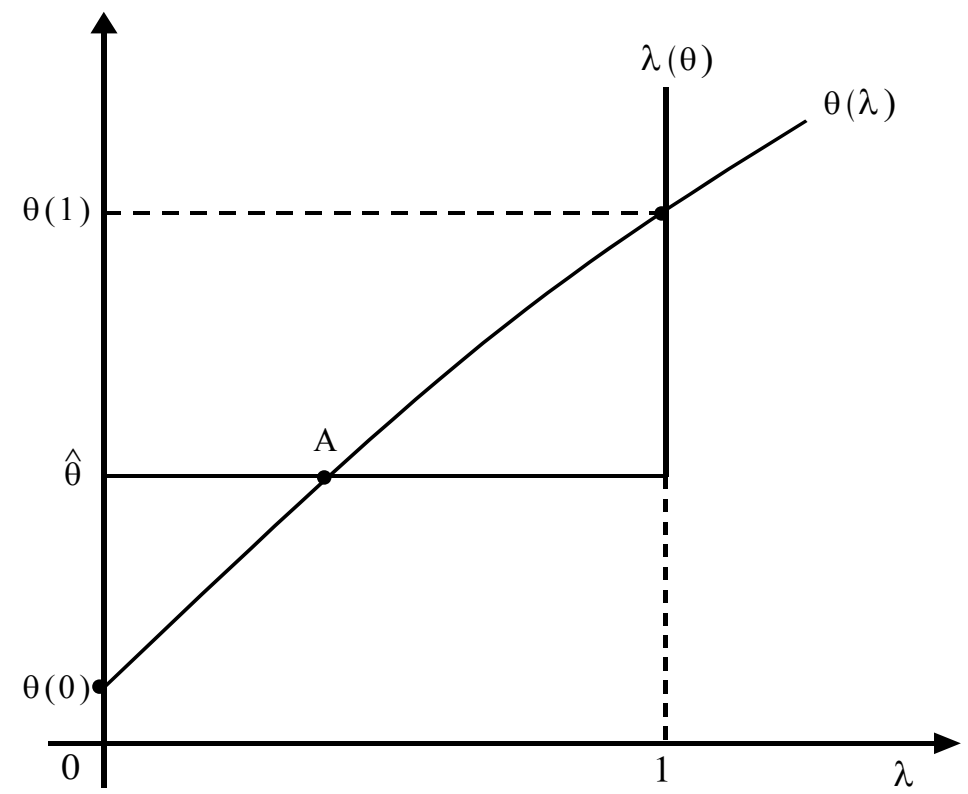

Figure 1: Multiple equilibria

which defines a unique level of labor market tightness, $\theta(\lambda)$, for each value of $\lambda$. The increasing schedule $\theta(\lambda)$ is also depicted in Figure 1.

Equilibria in this extended version of the model correspond to the intersections of $\lambda(\theta)$ and $\theta(\lambda)$. If the critical value $\widehat{\theta}$ falls on either side of the range of variation of the $\theta(\lambda)$ function, $[\theta(0), \theta(1)]$, then there is a unique intersection at one of the vertical segments of $\lambda(\theta)$, which corresponds to a unique equilibrium with either $\lambda=1$ (and high tightness) or $\lambda=0$ (and low tightness). When instead $\widehat{\theta}$ falls within the $[\theta(0), \theta(1)]$ interval, there are three intersections, as depicted in Figure 1. The equilibrium which corresponds to a point like $A$, however, is unstable and we will subsequently ignore it, focusing our discussion on the equilibria that occur on the vertical segments of $\lambda(\theta)$. Clearly, the equilibrium with $\lambda=1$ involves a lower use of social contacts (and thus greater expected productivity per occupied worker) and greater labor market tightness than the equilibrium with $\lambda=0$.

To understand the multiplicity, notice the self-reinforcing logic of each equilibrium. When more workers exploit their productive advantage, the expected productivity of a 
newly hired worker increases, so firms create more vacancies; but then finding a job is easier and workers are, indeed, more inclined to exploit their productive advantage. In most cases, the multiple equilibria can be Pareto ranked. In Appendix 1 we prove that the ranking depends critically on the relationship between $\beta$ and $\eta(\theta)$. In particular, if $\beta>\eta(\theta)$, which implies that the economy suffers from insufficient vacancy creation, the equilibrium in which more workers exploit their productive advantage, $\lambda=1$, is superior, since it helps sustain a larger level of labor market tightness, $\theta \cdot{ }^{9}$ In this case, a subsidy to worker's occupational mobility or other policies directed to weaken the influence of social contacts on occupational choices may increase social welfare.

Interestingly, the existence of the equilibrium with a lower use of social contacts $(\lambda=1)$ is negatively affected by the proportion of workers with a high endowment of contacts, $\mu$, since both $\theta(0)$ and $\widehat{\theta}$ are independent of $\mu$, while $\theta(1)$ is decreasing in $\mu$. Thus if, starting from a situation such as the one depicted in Figure 1, $\mu$ increases, a point can be reached where only the equilibrium in which all workers use their contacts $(\lambda=0)$ exists. This identifies a further dimension along which the abundance of social contacts may prevent an efficient functioning of the labor market.

\section{Empirical results}

One key implication of the previous analysis is that social contacts induce mismatch between workers' productive advantage and their actual occupational choice. As shown in Propositions 1 and 2, this mismatch implies that, on average, jobs found through contacts are obtained more quickly but also pay lower wages, since at least some of them are filled by workers who sacrificed their productive advantage in order to get a job more easily. After describing the data, this section is devoted to testing these and some further implications of our theory.

\footnotetext{
${ }^{9}$ If $\beta<\eta(\theta)$, then the economy suffers from excessive creation of vacancies and, thus, the opposite is true: the equilibrium with $\lambda=0$ is Pareto superior to that with $\lambda=1$. Finally, if one equilibrium suffers from too little vacancy creation and the other from too much, then the different equilibria cannot be Pareto ranked.
} 


\subsection{Data}

Our primary dataset is the "Multi-City Study of Urban Inequality, 1992-1994" (MCSUI), a survey carried out by the Inter-University Consortium for Political and Social Research at some different points in time over those three years in four US cities - Atlanta, Boston, Detroit, and Los Angeles. ${ }^{10}$ The survey includes the question "Did you find your (last/present) job through friends or relatives, other people, newspaper ads, or some other way?" that allows the following five possible answers: (1) Friends or relatives, (2) Other persons, (3) Newspaper ads, (4) Other, and (5) Refused/Don't know/Missing." To identify jobs founds through social contacts, we construct our key variable Contacts as a dummy taking the value one if the reply is (1) and zero if it is (2) through (4). ${ }^{11}$

The initial sample includes 8,916 observations but, for various reasons, our final sample is reduced to 891 observations. First, the questions about jobfinding methods were not asked in Detroit and they were asked to only 3,442 individuals in the other three cities. The availability of reliable data about wages (see Appendix 2) further reduced the sample to 2,766 observations, of which 1,804 correspond to currently employed workers (employees, on temporary layoff or on sickness/maternity leave). Since our model is intended to capture the occupational choices of workers early in their careers, we focused on individuals younger than 35 years old, which leaves us with 985 observations. Lastly, for part of the analysis described below we need information on the number of older siblings, which leads to the final sample of 891 observations (886 observations when industry dummies are included). Our key Contacts variable takes value one for $49.6 \%$ of the workers in this final sample.

To check the robustness of our results to variation in the institutional framework, we also use the European Community Household Panel (ECHP). We use the yearly waves for 1994 to 1998, corresponding to 13 European Union (EU) countries (Austria,

\footnotetext{
${ }^{10}$ For a more detailed description of the data, see Bobo et al. (2000).

${ }^{11}$ To check our results, we also consider an alternative definition based on assigning 1 to answers (1) and (2) to the following question: "Which of the following best describes your relationship to the one person who most directly helped you get your (last/current) job?: (1) Relative, (2) Friend, (3) Acquaintance, (4) Someone else, and (5) Refused/Don't know/Missing."
} 
Belgium, Denmark, Finland, France, Greece, Netherlands, Luxembourg, Ireland, Italy, Portugal, United Kingdom, and Spain). The survey provides information on personal characteristics of household members and, for employed workers, on jobfinding methods. It includes the question: "By what means were you first informed about your present job?", allowing the answers: (1) Applying to the employer directly, (2) Inserting or answering adverts in newspapers, TV, or radio, (3) Through an employment or vocational guidance agency, (4) Through family, friends or other contacts, (5) Started own business or joined family business, (6) Other, and (7) Missing." In this case we construct Contacts as a dummy taking the value one if the reply is (4) and zero for (1) through (3) and (6).

Initially there were 121,421 observations with information on all regressors, which become 120,893 after dropping unreliable wage observations. Thanks to its large size, the ECHP allows us to focus more closely on the target population of young workers choosing their occupation. In particular, we restrict the sample to workers aged 16 to 29 years old (36,111 observations) who are observed in their first permanent job $(7,764$ observations). Lastly, in order to analyze unemployment duration, we just take the workers with a previous unemployment spell, which brings the final sample to 1,859 observations. $^{12}$ In this sample, the fraction of workers who find their jobs through contacts is $34.5 \%$. This is lower than in the US, which may reflect the difference in the composition of the two samples.

Table 2 reports some descriptive statistics for the variables used as regressors in the wage and unemployment duration equations below -including the usual Mincer regressors. We describe separately the samples of workers who did and did not find their jobs through contacts. For the US, these variables are the years of formal education (Schooling) and labor market Experience (current age minus the age at which the person first left full-time education and was not in school for 16 months or more), race (White, Black, Asian, and Other, which includes Hispanics and Native Americans), gender (Male), be-

\footnotetext{
${ }^{12}$ The inclusion of industry and occupation dummies reduces the sample slightly further.
} 
ing US born, and working for a Small firm (defined as having less than 100 employees). ${ }^{13}$ The table shows that those who found jobs through contacts are slightly younger, less educated, more experienced, more likely to be male, less likely to be white, black or Asian rather than Hispanic or Native American, and less likely to have been born in the US. They also tend to work more in small firms. These characteristics are consistent with what has typically been found in the literature (see, for instance, Holzer, 1988).

For the EU data race is not available, and schooling is measured by the highest level of education completed rather than the number of years of education (this enhances comparability across countries with different education systems). In this sample, workers are on average about 3 years younger than in the US sample, but the statistics show roughly the same picture as for the US data.

\subsection{The average wage discount on contact jobs}

To test that jobs found through social contacts pay on average a lower wage than jobs found through formal channels (Proposition 1), we estimate the following regression, separately for the US and the EU:

$$
w_{i j t}=\psi+\alpha \text { Contacts }_{i j t}+\delta X_{i j t}+u_{i j t}
$$

where $w$ denotes the log wage and $X$ the vector of control variables. $i$ denotes individuals, $j$ denotes US cities or, alternatively, EU countries, and $t$ denotes time. For both the US and the EU, the dependent variable is the pre-tax hourly wage. In the baseline specification $X$ includes the variables which appear in Table 2 together with Experience squared and six firm-size categories intended to control for firm heterogeneity. In a second specification we add industry dummies, and a third specification further includes occupation dummies. The US data exhibits no time variation within locations since it is a cross-section for each city, while for the EU data is a panel with up to five years of observations, $t=1994, \ldots, 1998$. Thus, we include in $X$ a set of city dummies in the US specification and a full set of year and country dummies in the EU specification. All variable definitions and classifications are detailed in Appendix 2.

\footnotetext{
${ }^{13}$ In the empirical estimation we use a finer firm size classification, see below.
} 
We are interested in the coefficient on Contacts, which according to the model should be negative, since it captures the effect of workers' self-selection into occupations in which they have contacts but may fail to exploit their comparative productive advantage. The specifications with industry and occupation dummies intend to further control for workers' individual abilities (say, parameter $y$ in the model), and reflect the fact that social contacts tend to distort occupational choices within any industry or skill category.

In our US regression sample, hourly wages for those who found a job through contacts are on average $24.1 \%$ lower than for those who did otherwise. After controlling for the city, the (log) discount falls to $20.7 \%$. As Table 3 shows, once we add the usual Mincer regressors, it drops to $6.8 \%$ and it remains around $6 \%$ after adding industry and occupation dummies.

EU data yields similar estimates. The raw average wage discount on contact jobs is $24.9 \%$, falling to $8.9 \%$ once we control for year and country. Adding the standard regressors brings it further down to $6.5 \%$, and including industry and occupation dummies leads it to stabilize around 5\%. The discount, present in US and EU data, is both economically and statistically significant, providing a first piece of evidence consistent with our theory.

According to our interpretation, the negative coefficient on Contacts is the result of occupational choices, which are typically long-term decisions. In this sense we would expect the wage discount to persist over time. If this interpretation is correct, the discount should not die out as time passes. To check this, we introduced in the regression the interaction between Contacts and Experience, and, indeed, its coefficient turned out to be small and not statistically significant. ${ }^{14}$

\subsection{Social contacts help find jobs}

We also test that workers who find jobs through contacts exhibit lower unemployment duration than workers who find jobs through other channels (Proposition 2). The fact

\footnotetext{
${ }^{14}$ For example, in the specification including industry and occupation dummies, the US coefficient was $0.7 \%$ with a $t$-ratio of 1.37 , while the EU coefficient was $-0.2 \%$, with a $t$-ratio of 0.48 .
} 
that social contacts are useful for jobfinding has been documented before for the US, see e.g. Holzer (1988). However, it is useful to check it within the same samples that lead to our results on wages so as to fully document the trade-off that our theory postulates: contacts help workers find a job more quickly, but those jobs pay lower wages. So we estimate a regression of the duration of the unemployment spell preceding the current job, on the same control variables as in the wage equation (17), and we test whether the coefficient on Contacts is negative. ${ }^{15}$

For the US, even though the sample selection criteria are the same as for the wage regression, the number of observations including information on unemployment spell duration is about one-fourth as for wages. For this reason we use less disaggregate industry and occupation classifications (see Appendix 2 for a definition of the grouped industry and occupation categories). In this sample, unemployment spells for individuals who found their jobs through contacts are on average $12 \%$ shorter than for those who did otherwise. Panel A of Table 4 shows that, after introducing the control variables, the unemployment spell shortening due to contacts is statistically significant and amounts to about 55 days, which represents $27 \%$ of the average unemployment spell duration of the reference individual.

For the EU, the raw unemployment duration of workers who found their job through contacts is on average $2 \%$ lower than for those who did otherwise. As presented in Panel $\mathrm{B}$ of Table 4, however, once the controls are included, the reduction in duration amount to about one month, which is $11 \%$ of the duration of the reference worker.

Given the magnitude of the wage discount and its persistence, these effects on unemployment duration suggest that, in line with the idea formalized in Section 4, occupations related to the worker's social contacts render sizable nonpecuniary benefits to him or her.

\footnotetext{
${ }^{15}$ The regression is run on observations corresponding to workers with a previous unemployment spell. Not observing such a spell may respond to a variety of situations, including a direct move from out of the labor force (OLF) into employment, for which one might expect contacts to have a positive effect. These direct moves can only be identified in the EU data, where we found a positive, albeit not significant, effect of contacts on the likelihood of having moved to employment directly from OLF rather than through an unemployment spell. The lack of significance of this effect is not surprising given that being OLF is, in many cases, hardly distinguishable from being unemployed (see Norwood, 1988).
} 


\subsection{Further evidence about the wage discount}

The US sample allows us to perform a couple of robustness checks that will bring us closer to the mechanism highlighted by the model. First, as noted in the Introduction, a large share of the literature has focused on employee referrals, which, for their information content, are expected to have a positive effect on wages. In order to purge the Contacts variable of referral effects, we add to the wage equation the interaction of Contacts with a dummy variable indicating whether the contact person worked for the worker's employer, i.e. whether he or she was an Insider. Our results are summarized in Panel A of Table 5. Consistent with the usual findings in the literature, this interaction enters with a positive (albeit not significant) coefficient while, importantly, the magnitude of Contacts increases in absolute value.

Another implication of our theory is that individuals with a larger endowment of contacts may sacrifice more of their productive advantage. Thus the wage discount associated to contact jobs should be increasing in the worker's endowment of contacts. To test this prediction in the US dataset, we use as a proxy for the stock of social contacts the number of siblings older than the worker. The idea is that older siblings are likely to have entered the labor market before, providing the worker with information about the vacancies available in the specific segments of the labor market that they know. To capture this effect we estimate the following equation:

$$
w_{i j t}=\psi+\alpha \text { Contacts }_{i j t}+\sigma \text { Contacts }_{i j t} \text { Sib }_{i j t}+\delta X_{i j t}+u_{i j t}
$$

where Sib is a dummy which takes the value zero for individuals with no older siblings and one for those with some older siblings. The mechanism highlighted in the model would imply that $\sigma$ is negative and significant. To control for potential direct productivity effects of the number of siblings (e.g., due to the resources that parents devote to the education of each child), we also include Sib on its own, which does not turn out to be significant.

Panel B of Table 5 shows the wage effect of Contacts on individuals without older siblings, $\alpha$, and the compounded effect for those with older siblings, $\alpha+\sigma$. The former 
is never statistically significant and it is always lower than the latter, which is again consistent with the theory. However, the equality of the two coefficients cannot be rejected, due to the large standard error around the coefficient for workers without older siblings.

\subsection{Controlling further for unobserved heterogeneity}

We now further check that the wage discount on contact jobs arises from mismatch rather than from a spurious correlation due to unobserved heterogeneity, say because workers' intrinsic productivity ( $y$ in the model) and their endowment of contacts $(\tilde{s}$ in the model) are negatively correlated.

In light of the recent debate about the effect of measures of cognitive abilities on wages (see, for example, Cawley et al., 1997), we address this issue by adding in the US regressions (the EU data do not contain such information), first the worker's average high school grade and secondly the interviewer's perception of the worker's ability to speak clearly in English. ${ }^{16}$ For obvious reasons, the first variable is only considered in the subsample of workers having at least a high school degree, while the second is considered in the full sample.

For both the high school grade and the ability to speak clearly in English, we first run a linear probability model to see whether the two variables affect the probability of finding a job through contacts. After controlling for all the other variables included in the wage equation, we find that both variables negatively affect the probability of finding a job through contacts, although the effect of high school grades is not statistically significant. ${ }^{17}$ More importantly, we find a positive effect of both the high school grade and the ability to speak in English on wages but, as shown in Table 6, the inclusion of these variables leaves the coefficient on Contacts essentially unaffected. In other words, it does not seem that the omission of workers' intrinsic productivity explains the wage

\footnotetext{
${ }^{16}$ See Appendix 2 for data definitions. We also replaced the second variable by the interviewer's perception of the worker's ability to understand English, and the results were essentially the same.

${ }^{17}$ Specifically, the coefficient on school grades is around $-1 \%$ with a $t$-ratio about 0.7 , while the coefficient on the ability to speak English is $-4.8 \%$, with a $t$-ratio of 2.5 .
} 
discount on contact jobs.

To further test the orthogonality between the wage discount and workers' intrinsic productivity, we also tried interacting the high school grade and the ability to speak clearly in English with Contacts. It turned out that both interactions were small and not significantly different from zero, thereby reinforcing our previous conclusion, which leaves mismatch as the more plausible explanation.

\subsection{The aggregate effects of social contacts}

A further implication of our theory is that an increase in the workers' endowment of contacts leads to a reduction in aggregate productivity and in firms' investment if capital is endogenous. These aggregate effects imply that regions or countries with a higher fraction of jobs found through social contacts should also have lower average wages. Importantly, the magnitude of the effect should be greater than what would result from the simple aggregation of the micro wage regressions in equation (17).

To test this implication we use the EU database, which provides data for 46 regions (see Appendix 2). Given the relatively small number of region-year pairs available (157), we use grouped industries and occupations. We run a regression for average regional hourly wages on the regional averages of the controls included in the wage regressions in Table 3. The test amounts to checking whether the effect on average regional wages of the fraction of workers who found their job through contacts is larger in absolute value than in the individual-level wage regressions. Table 7 shows that this is indeed the case, which is again favorable to the model. The coefficient is large, around $23 \%$, but it is imprecisely estimated, so that the difference with respect to the individual wage estimates is only borderline statistically significant (see the $p$-values in the last column of Table 7).

\section{Conclusions}

It is well known that friends and relatives are often a source of useful information for finding jobs. Previous research has emphasized the positive effects of these social con- 
tacts in the process of jobfinding. In this paper we highlight another effect of social contacts, namely that, as they tend to be occupation specific, they induce some workers to undertake careers in industries, professions, or firms where their comparative productive advantage is not fully exploited. And the sacrifice in terms of productivity may be even larger if, in addition, individuals feel pressed, or prefer, to choose occupations close to those of their friends and relatives (say, in order to comply with social conventions or family traditions). Thus, in economies with dense social networks, some individuals will not fully exploit their productivity potential. Consequently, the labor market will be characterized by a high degree of mismatch, which in turn will depress aggregate productivity and the returns to firms' investment.

We have shown, with both US and European Union data, that there is indeed a wage discount of around $5 \%$ to $7 \%$ for jobs found through contacts. This evidence is reinforced once we control for whether the contact person was working at the same firm (which should purge the positive effect of referrals). The evidence for both the US and Europe also supports the presence of a trade-off between quicker jobfinding and lower wages. We have also shown that the wage discount on contact jobs persists over time, is increasing in the worker's endowment of contacts (as captured, for instance, by the number of older siblings), and is largely orthogonal to measures of individual cognitive ability. Overall, the evidence supports the claim that social contacts tend to distort workers' occupational choices, inducing mismatch. Additionally, for European regions we have also found evidence of negative externalities since the regional importance of contacts for jobfinding depresses average regional wages beyond what would result from the simple aggregation of the wage discounts estimated with individual-level data. 


\section{Appendix 1. Proofs}

Proof of $E(d \mid c=1)-E(d \mid c=0) \leq 0$ From (8) and (9), one can obtain:

$$
E(d \mid c=1)-E(d \mid c=0)=\frac{(1-\mu)\left\{2 \rho \mu s S-\mu S^{2}-[1-(1-\mu) \rho] \rho s^{2}-(1-\rho) S s[\mu S+(1-\mu) \rho s]\right\}}{p(\theta)(1+S)(1+s)[\mu S+(1-\mu) \rho s]} .
$$

The sign of this expression is clearly given by that of the expression within curly brackets in the numerator. Such an expression has a derivative with respect to $\mu$ equal to

$$
2 \rho s S-S^{2}-\rho^{2} s^{2}-(1-\rho) S s(S-\rho s)=-(S-\rho s)^{2}-(1-\rho) S s(S-\rho s)
$$

which is negative for any $S>s$ and $\rho \in[0,1]$. But the expression in curly brackets in the numerator is clearly negative at $\mu=0$,

$$
-[1-\rho] \rho s^{2}-(1-\rho) \rho s^{2} S,
$$

so $E(d \mid c=1)-E(d \mid c=0) \leq 0$ for all $\mu \in[0,1]$.

Efficiency when contacts yield some non job-search benefits When the use of contacts yields some private benefits $b$, social welfare is equal to

$$
W=2\{p(\theta)[1+\gamma(\lambda) a] y-k \theta\} U
$$

where $U$ denotes the total number of efficiency units of search in the market for each occupation which is equal to

$$
U=\mu \rho(1+S)+(1-\mu) \rho(1+s)+\mu(1-\rho)(1+S)+(1-\mu)(1-\rho)[(1-\lambda)(1+s)+\lambda] .
$$

By deriving in (15) with respect to $\theta$ and after using (16) we obtain that

$$
\frac{\partial W}{\partial \theta}=\frac{2 k[\beta-\eta(\theta)] U}{1-\beta}
$$

which is identical to (11). By deriving in (15) with respect to $\lambda$ and after using (16) we obtain that

$$
\frac{\partial W}{\partial \lambda}=(1-\mu)(1-\rho)[p(\theta)(a-s) y-b]
$$

which is positive if $p(\theta)>\hat{p}=b /[(a-s) y]$ and negative otherwise, that proves that the choice of $\lambda$ in the competitive economy is efficient conditional on $\theta$. 


\title{
Appendix 2. Data classifications and definitions
}

\author{
United States (Multi-City Study of Urban Inequality)
}

Wages: Pre-tax hourly wage including tips and bonuses, computed as the total amount divided by the reported number of hours. We exclude observations flagged by the survey as possible data entry errors, i.e. when the computed wage is greater than $\$ 50$ per hour and not reasonable based on the respondent's occupation, or it is less than $\$ 2$ per hour. Firm size dummies: 1-4, 5-19, 20-49, 5-99, 100-499, and 500 or more employees (which is the only information available in the ECHP).

Industries: (1) Agriculture, forestry, and fisheries, (2) Mining, (3) Construction, (4) Manufacturing, (5) Transportation, communications and other public utilities, (6) Wholesale trade, (7) Retail trade, (8) Finance insurance and real estate, (9) Business and repair services, (10) Personnel services, (11) Entertainment and recreation services, (12) Professional and related services, and (13) Public administration.

Grouped industries: Agriculture (1), Manufacturing (2,4), Construction (3), and Services (5-13).

Occupations: (1) Managerial, (2) Technical, (3) Services, (4) Farming, (5) Crafts, and (6) Operators.

Grouped occupations: White collar (1-3) and Blue collar (4-6).

Average high school grade: (1) D or lower, (2) C-/D+, (3) C, (4) B-/C+, (5) B, (6) $\mathrm{A}-/ \mathrm{B}+$, and (7) A.

Ability to speak clearly in English: (1) Poor, (2) Fair, (3) Good, (4) Very good, and (5) Excellent.

\section{European Union (European Community Household Panel)}

Wages: Net monthly wage divided by the total number of hours worked per month in the worker's main and additional jobs, expressed in a common currency (dollars). We delete monthly wages below $\$ 100$ and hourly wages below $\$ 1$.

Firm size dummies: as in the US.

Industries: (1) Agriculture, hunting, and forestry, Fishing, (2) Mining and quarrying, Electricity, gas, and water supply, (3) Manufacturing of food products, beverages, and tobacco, (4) Manufacturing of textiles, clothing, and leather products, (5) Manufacturing of wood and paper products, Publishing and printing, (6) Manufacturing of coke, Refined petroleum, Chemicals, Rubber and plastic, (7) Manufacturing of metal products, machinery, and equipment, (8) Other manufacturing, (9) Construction, (10) Wholesale and retail trade, Repair of motor vehicles, motorcycles, etc., (10) Hotels and restaurants, (11) Transport, storage, and Communications, (12) Financial intermediation, (13) Real estate, renting, and business activities, (14) Public administration and defense, Compulsory social security, (15) Education, (16) Health and social work, and (17) Other community, social, and personal service activities.

Grouped industries: Agriculture (1), Manufacturing (2-8), Construction (9), and Services $(10-17)$. 
Occupations: (1) Legislators and Managers, (2) Small firm managers, (3) Science and health professionals, (4) Teaching, (5) Other professionals, (6) Science and health associated professionals, (7) Teaching and other associate professionals, (8) Office and service clerks, (9) Personal and protective services, (10) Models, salespersons, (11) Skilled agriculture and fishery workers, (12) Extraction, building, and other craft, (13) Metal and precision, printing, etc., (14) Plant operators, drivers, (15) Machine operators, assemblers, (16) Miscellaneous operators, (17) Sales and service elementary tasks, (18) Agricultural and fishery laborers, (19) Mining, construction, manufacturing, and transport laborers, and (20) Miscellaneous laborers.

Grouped occupations: High skill (1-5), Medium skill (6-16), and Low skill (17-20). Regions: Aggregates available in the ECHP, i.e. NUTS 2 for Portugal, Sweden, and the United Kingdom, and NUTS 1 for the remaining countries except for Finland, Ireland, and the Netherlands where it is more aggregated. 


\section{References}

[1] Acemoglu, D. (1996), "A Micro-foundation for Social Increasing Returns in Human Capital Accumulation", Quarterly Journal of Economics 111, 779-804.

[2] Blau, D. and Robins, P. (1990), "Job Search Outcomes for the Employed and Unemployed", Journal of Political Economy 98, 637-55.

[3] Bobo, L., Johnson, J., Oliver, M., Farley, R., Bluestone, B., Browne, I., Danziger, S., Green, G. Holzer, H., Krysan, M., Massagli, M., and Zubrinsky, C. (2000), "Multi-City Study of Urban Inequality, 1992-1994 [Atlanta, Boston, Detroit, and Los Angeles]", Inter-University Consortium for Political and Social Research, Ann Arbor, MI.

[4] Borjas, G. (1995), "Ethnicity, Neighborhoods, and Human Capital Externalities", American Economic Review 85, 365-390.

[5] Calvo-Armengol, T. and Jackson, M. (2003), "Networks in Labor Markets: Wage and Employment Dynamics and Inequality", Mimeo, California Institute of Technology, http://www.hss.caltech.edu/ jacksonm/Jackson.html.

[6] Calvo-Armengol, T. and Jackson, M. (2004), "The Effects of Social Networks on Employment and Inequality", American Economic Review, forthcoming.

[7] Cawley, J., Conneely, K., Heckman, J., and Vytlacil E. (1997) "Cognitive Ability, Wages, and Meritocracy", in Devlin, B., Fienberg, S., Resnick, D., and Roeder, K. (eds.), Intelligence, Genes, and Success: Scientists Respond to The Bell Curve, New York: Springer Verlag.

[8] Coleman, J. (1988), "Social Capital in the Creation of Human Capital", American Journal of Sociology, 94, S95-S120.

[9] Corcoran, M., Datcher, L., and Duncan, G.J. (1980), "Information and Influence Networks in Labor Markets", in Duncan, G., and Morgan, J., (eds.), Five Thousand American Families: Patterns of Economic Progress, vol. 8, Ann Arbor, MI, Institute for Social Research.

[10] Granovetter, M.S. (1974), Getting a Job, Cambridge, MA, Harvard University Press.

[11] Guiso, L., Sapienza, P., and Zingales, L. (2000), "The Role of Social Capital in Financial Development", CEPR Discussion Papers 2383.

[12] Hall, R. and Jones, C. (1999), "Why do Some Countries Produce so Much More Output than Others?", Quarterly Journal of Economics 114, 83-116.

[13] Holzer, H. (1988), "Search Method Use by Unemployed Youth", Journal of Labor Economics 6, 1-20. 
[14] Hosios, A. (1990), "On the Efficiency of Matching and Related Models of Search and Unemployment", Review of Economic Studies 57, 279-298.

[15] Knack, S. and Keefer, P. (1997), "Does Social Capital Have an Economic Payoff? A Cross-Country Investigation", Quarterly Journal of Economics 112, 1251-88.

[16] Kugler, A. (2003), "Employee Referrals and Efficiency Wages", Labour Economics $10,531-556$

[17] Montgomery, J. (1991), "Social Networks and Labor-Market Outcomes: Toward an Economic Analysis", American Economic Review 81, 1408-1418.

[18] Marmaros, D. and Sacerdote, B. (2002), "Peer and Social Networks in Job Search", European Economic Review 46, 870-879

[19] Mortensen, D. and Vishwanath, T. (1994), "Personal Contacts and Earnings: It is Who you Know!", Labour Economics 1, 187-201.

[20] Munshi, K. (2003), "Networks in the Modern Economy: Mexican Migrants in the US Labour Market", Quarterly Journal of Economics 118, 549-99.

[21] Norwood, J. (1988), "The Measurement of Unemployment", American Economic Review 78, 284-88.

[22] Pellizzari, M. (2003), "Do Friend and Relatives Really Help in Getting a Good Job?", Mimeo, London School of Economics.

[23] Pissarides, C. (2000), Equilibrium Unemployment Theory, 2nd Edition, MIT Press.

[24] Pistaferri, L. (1999), "Informal Networks in the Italian Labor Market", Giornale degli Economisti 58, 355-75.

[25] Saloner, G. (1985), "Old Boy Networks as Screening Mechanism", Journal of Labor Economics 3, 255-267.

[26] Santamaria-Garcia, J. (2003), "Markets with Imperfections: Essays on Bargaining an Search", unpublished Ph.D. thesis, European University Institute, ch. 2.

[27] Simon, C. and Warner, J. (1992), "Matchmaker, Matchmaker: The Effect of Old Boy Networks on Job Match Quality, Earnings, and Tenure", Journal of Labor Economics 10, 306-330. 
Table 1. Equilibrium outcomes

\begin{tabular}{lcccc}
\hline \hline & \multicolumn{4}{c}{ Worker type } \\
\cline { 2 - 5 } & \multicolumn{2}{c}{ Many contacts $(S)$} & \multicolumn{2}{c}{ Few contacts $(s)$} \\
\cline { 2 - 5 } & \multicolumn{1}{c}{ No trade-off } & Trade-off & No trade-off & Trade-off \\
\hline Wage $(\beta y \times)$ & $1+a$ & 1 & $1+a$ & $1+a$ \\
Job finding prob. $(p \times)$ & $1+S$ & $1+S$ & $1+s$ & 1 \\
Expected utility $(p \beta y \times)$ & $(1+a)(1+S)$ & $1+S$ & $(1+a)(1+s)$ & $1+a$ \\
\hline Weight in population & $\mu \rho$ & $\mu(1-\rho)$ & $(1-\mu) \rho$ & $(1-\mu)(1-\rho)$ \\
Weight in search units & $\mu \rho(1+S)$ & $\frac{\mu(1-\rho)(1+S)}{\mu(1+S)+(1-\mu)(1+\rho s)}$ & $\frac{(1-\mu) \rho(1+s)}{\mu(1+S)+(1-\mu)(1+\rho s)}$ & $\frac{(1-\mu)(1-\rho)}{\mu(1+S)+(1-\mu)(1+\rho s)}$ \\
Weight in employment & $\frac{\mu \rho(1+S)}{\mu(1+S)+(1-\mu)(1+\rho s)}$ & $\frac{\mu(1-\rho)(1+S)}{\mu(1+S)+(1-\mu)(1+\rho s)}$ & $\frac{(1-\mu) \rho(1+s)}{\mu(1+S)+(1-\mu)(1+\rho s)}$ & $\frac{(1-\mu)(1-\rho)}{\mu(1+S)+(1-\mu)(1+\rho s)}$ \\
Weight in $c=1$ workers & $\frac{\mu \rho S}{\mu S+(1-\mu) \rho s}$ & $\frac{\mu(1-\rho) S}{\mu S+(1-\mu) \rho s}$ & $\frac{(1-\mu) \rho s}{\mu S+(1-\mu) \rho s}$ & 0 \\
Weight in $c=0$ workers & $\mu \rho$ & $\mu(1-\rho)$ & $(1-\mu) \rho$ & $(1-\mu)(1-\rho)$ \\
\hline \hline
\end{tabular}


Table 2. Sample characteristics of the data

\begin{tabular}{lrrrr}
\hline \hline Jobs found through: & \multicolumn{3}{c}{ Other channels } & \multicolumn{2}{c}{ Contacts } \\
\cline { 2 - 5 } & Mean & St.dev. & Mean & St.dev. \\
\hline A. United States: & & & & \\
Age & 87.9 & 3.9 & 27.3 & 3.9 \\
Experience & 13.5 & 4.8 & 8.7 & 4.7 \\
Schooling & 33.2 & & 12.2 & 3.0 \\
White & 31.0 & & 22.2 & \\
Black & 12.0 & & 6.2 & \\
Asian & 23.8 & & 45.2 & \\
Other race & 47.4 & & 55.4 & \\
Male & 66.6 & & 50.2 & \\
Born in the US & 63.5 & & 72.9 & \\
Works for a small firm & 10.5 & 5.2 & 8.5 & 4.3 \\
Hourly wage & 89.9 & 209.3 & 79.3 & 234.3 \\
Unemployment duration* & 449 & & 442 & \\
No. of observations & & & & \\
& & & & \\
B. European Union: & & & & \\
Age & 4.4 & 3.0 & 24.2 & 3.2 \\
Experience & 3.4 & 4.5 & 3.4 \\
Less than 2nd stage, 2nd educ. & 27.4 & & 35.5 & \\
2nd stage, 2nd education & 51.8 & & 47.7 & \\
3rd level education & 20.8 & & 16.8 & \\
Male & 50.0 & & 53.9 & \\
Born in the country of residence & 96.2 & & 95.6 & \\
Works for a small firm & 70.8 & & 87.4 & \\
Hourly wage & 5.8 & 2.6 & 4.6 & 2.1 \\
Unemployment duration & 9.5 & 7.7 & 9.3 & 7.4 \\
No. of observations & 1217 & & 642 & \\
\hline \hline
\end{tabular}

Note. Age, experience are in years, hourly wages are in dollars. Schooling is in years for the US. Unemployment duration is in days for the US and in months for the EU. The remaining variables are percentage shares. ${ }^{*}$ The sample size for unemployment duration in the US is 111 for other channels and 99 for contacts. 
Table 3. The discount on contact jobs

Dependent variable: log hourly wage

\begin{tabular}{lcccc}
\hline \hline Coefficient on Contacts (\%): & Coeff. & $t$ & $\bar{R}^{2}$ & Obs. \\
\hline A. United States: & & & & \\
& & & & \\
Baseline & -6.77 & $(2.50)$ & 0.35 & 891 \\
With industry dummies & -7.72 & $(2.90)$ & 0.35 & 886 \\
With industry and occupation dummies & -6.14 & $(2.35)$ & 0.40 & 886 \\
& & & & \\
B. European Union: & & & & \\
& & & & \\
Baseline & -6.47 & $(3.42)$ & 0.67 & 1859 \\
With industry dummies & -5.20 & $(2.83)$ & 0.69 & 1845 \\
With industry and occupation dummies & -4.94 & $(2.69)$ & 0.71 & 1813 \\
\hline \hline
\end{tabular}

Note. OLS regressions. The baseline specification includes: (a) For the US: a constant, city dummies (omitted: Atlanta), years of schooling, experience, experience squared, race dummies (white, black, Asian; omitted: others), a gender dummy (male; omitted: female), a dummy for being born in the US, and 6 firm size dummies (omitted: 1-4 employees). (b) For the EU: a constant, year dummies, country dummies (omitted: Denmark), schooling dummies (Third level education, Second stage of secondary level education; omitted: Less than secondary level education), experience, experience squared, a gender dummy (male; omitted: female), a dummy for being born in the country of residence, and 6 firm size dummies (omitted: 1-4 employees). The second line for each area contains industry dummies (12 in the US, 16 in the EU; omitted: Agriculture) and the third line both industry and occupation dummies (5 in the US; omitted: operators, and 19 in the EU; omitted: miscellaneous labourer). See Appendix 2 for definitions. For the EU, robust standard errors, adjusted for repeated observations on the same worker, are reported. 
Table 4. The tradeoff: contacts and unemployment duration

Dependent variable: unemployment duration

\begin{tabular}{lcccc}
\hline \hline Coefficient on Contacts: & Coeff. & $t$ & $\bar{R}^{2}$ & Obs. \\
\hline A. United States (days): & & & & \\
& & & & \\
Baseline & -58.40 & $(2.29)$ & 0.00 & 206 \\
With industry dummies & -55.43 & $(2.13)$ & 0.00 & 204 \\
With industry and occupation dummies & -55.42 & $(2.12)$ & 0.00 & 204 \\
& & & & \\
B. European Union (months): & & & & \\
& -1.22 & $(2.31)$ & 0.16 & 1860 \\
Baseline & -0.97 & $(1.86)$ & 0.19 & 1846 \\
With industry dummies & -1.00 & $(1.92)$ & 0.21 & 1814 \\
With industry and occupation dummies & & & & \\
\hline \hline
\end{tabular}

Note. OLS regressions. The baseline specification includes: (a) For the US: a constant, dummies for living in Boston and Los Angeles (omitted: Atlanta), years of schooling, experience, experience squared, race dummies (white, black, Asian; omitted: others), a gender dummy (male; omitted: female), a dummy for being born in the US, and a dummy for working for a small firm. (b) For the EU: a constant, year dummies, country dummies (omitted: Denmark), schooling dummies (Third level education, Second stage of secondary level education; omitted: Less than secondary level education), experience, experience squared, a gender dummy (male; omitted: female), a dummy for being born in the country of residence, and 6 firm size dummies (omitted: 1-4 employees). The second line for each area contains industry dummies (3 in the US, 16 in the EU; omitted: agriculture) and the third line both industry and occupation dummies (1 in the US, omitted: blue collar, and 19 in the EU, omitted: miscellaneous labourer). See Appendix 2 for definitions. For the EU, robust standard errors, adjusted for repeated observations on the same worker, are reported. 
Table 5. The discount on contact jobs: robustness checks for the US Dependent variable: log hourly wage

\begin{tabular}{|c|c|c|c|c|}
\hline Coefficient on Contacts (\%): & Coeff. & $t$ & $\bar{R}^{2}$ & Obs. \\
\hline \multicolumn{5}{|l|}{ A. Controlling for insiders: } \\
\hline Baseline & -7.12 & $(1.75)$ & 0.34 & 891 \\
\hline With industry dummies & -8.73 & $(2.17)$ & 0.37 & 886 \\
\hline With industry and occupation dummies & -6.80 & $(1.71)$ & 0.40 & 886 \\
\hline \multicolumn{5}{|c|}{ B. Splitting the effect according to number of siblings: } \\
\hline Baseline & & & 0.37 & 891 \\
\hline • No siblings & -5.57 & $(1.17)$ & & \\
\hline - One or more siblings & -7.39 & $(2.29)$ & & \\
\hline Test for equality ( $p$-value) & & 0.74 & & \\
\hline With industry dummies & & & 0.38 & 886 \\
\hline - No siblings & -5.52 & $(1.17)$ & & \\
\hline - One or more siblings & -9.03 & $(2.84)$ & & \\
\hline Test for equality ( $p$-value) & & 0.49 & & \\
\hline With industry and occupation dummies & & & 0.40 & 886 \\
\hline • No siblings & -2.56 & $(0.56)$ & & \\
\hline - One or more siblings & -7.87 & $(2.52)$ & & \\
\hline Test for equality ( $p$-value) & & 0.33 & & \\
\hline
\end{tabular}

Note. OLS regressions. Regressions in Panel A include the interaction of Contacts with Insider, i.e. a dummy variable which takes the value 1 if the contact person worked at the same firm where the employee works; in Panel B a dummy that takes the value 1 if the worker has any siblings. As in Table 3, the baseline specification includes a constant, city dummies (omitted: Atlanta), years of schooling, experience, experience squared, race dummies (white, black, Asian; omitted: others), a gender dummy (male; omitted: female), a dummy for being born in the US, and 6 firm size dummies (omitted: 1-4 employees). The second specification adds 12 industry dummies (omitted: agriculture) and the third 5 occupation dummies (omitted: operators). See Appendix 2 for definitions. 
Table 6. The discount on contact jobs:

checks for unobserved ability for the US

Dependent variable: log hourly wage

\begin{tabular}{lcccc}
\hline \hline Coefficient on Contacts (\%): & Coeff. & $t$ & $\bar{R}^{2}$ & Obs. \\
\hline A. Controlling for the average high school grade: & & & \\
& & & & \\
Baseline & -6.25 & $(2.09)$ & 0.32 & 714 \\
With industry dummies & -7.73 & $(2.66)$ & 0.36 & 711 \\
With industry and occupation dummies & -6.46 & $(2.25)$ & 0.41 & 711 \\
& & & \\
B. Controlling for the ability to speak clearly in English: & & \\
Baseline & & & & \\
With industry dummies & -6.09 & $(2.14)$ & 0.34 & 799 \\
With industry and occupation dummies & -6.49 & $(2.66)$ & 0.36 & 794 \\
\hline \hline
\end{tabular}

Note. OLS regressions. Regressions in Panel A include the high school grade as a control, in Panel B they include the ability to speak clearly in English. As in Table 3, the baseline specification includes a constant, city dummies (omitted: Atlanta), years of schooling, experience, experience squared, race dummies (white, black, Asian; omitted: others), a gender dummy (male; omitted: female), a dummy for being born in the US, and 6 firm size dummies (omitted: 1-4 employees). The second specification adds 12 industry dummies (omitted: agriculture) and the third 5 occupation dummies (omitted: operators). See Appendix 2 for definitions. 
Table 7. The regional contacts discount in Europe

Dependent variable: log average regional hourly wage

\begin{tabular}{lccccc}
\hline \hline Coefficient on Contacts (\%): & Coeff. & $t$ & $\bar{R}^{2}$ & Obs. & $\begin{array}{c}\text { Test for } \\
\text { Agg. eff. }\end{array}$ \\
\hline Baseline & -23.71 & $(1.89)$ & 0.93 & 157 & 0.09 \\
With industry dummies & -24.70 & $(1.89)$ & 0.93 & 157 & 0.07 \\
With industry and occupation dummies & -22.55 & $(1.75)$ & 0.93 & 157 & 0.09 \\
\hline \hline
\end{tabular}

Note. OLS regressions. The baseline specification includes a constant, year dummies, country dummies (omitted: Denmark), regional average experience, and the regional fractions in the reference population who are: in schooling groups (Third level education, Second stage of secondary level education), male, born in the country of residence, and working for a small firm. The second line for each area contains regional fractions in 3 industry dummies (omitted: agriculture) and the third line the fractions in 2 occupation dummies (omitted: low skill) as well. See Appendix 2 for definitions. The last column shows the p-value of a one-sided test for the aggregate effect, whether the estimated coefficient is significantly larger than the point-value of the equivalent estimated coefficients in Panel B of Table 3 (individual wage regressions): i.e. $-6.47,-5.21$, and -4.94 , respectively. Robust standard errors, adjusted for repeated observations on the same region, are reported. 


\section{CEMFI WORKING PAPERS}

0101 Manuel Arellano: "Discrete choices with panel data".

0102 Gerard Llobet: "Patent litigation when innovation is cumulative".

0103 Andres Almazán and Javier Suarez: "Managerial compensation and the market reaction to bank loans".

0104 Juan Ayuso and Rafael Repullo: "Why did the banks overbid? An empirical model of the fixed rate tenders of the European Central Bank".

0105 Enrique Sentana: "Mean-Variance portfolio allocation with a Value at Risk constraint".

0106 José Antonio García Martín: "Spot market competition with stranded costs in the Spanish electricity industry".

0107 José Antonio García Martín: "Cournot competition with stranded costs".

0108 José Antonio García Martín: "Stranded costs: An overview”.

0109 Enrico C. Perotti and Javier Suárez: "Last bank standing: What do I gain if you fail?".

0110 Manuel Arellano: "Sargan's instrumental variable estimation and GMM".

0201 Claudio Michelacci: "Low returns in R\&D due to the lack of entrepreneurial skills".

0202 Jesús Carro and Pedro Mira: "A dynamic model of contraceptive choice of Spanish couples".

0203 Claudio Michelacci and Javier Suarez: "Incomplete wage posting".

0204 Gabriele Fiorentini, Enrique Sentana and Neil Shephard: "Likelihood-based estimation of latent generalised ARCH structures".

0205 Guillermo Caruana and Marco Celentani: "Career concerns and contingent compensation".

0206 Guillermo Caruana and Liran Einav: "A theory of endogenous commitment".

0207 Antonia Díaz, Josep Pijoan-Mas and José-Víctor Ríos-Rull: "Precautionary savings and wealth distribution under habit formation preferences".

0208 Rafael Repullo: "Capital requirements, market power and risk-taking in banking".

0301 Rubén Hernández-Murillo and Gerard Llobet: "Patent licensing revisited: Heterogeneous firms and product differentiation".

0302 Cristina Barceló: "Housing tenure and labour mobility: A comparison across European countries".

0303 Víctor López Pérez: "Wage indexation and inflation persistence".

0304 Jesús M. Carro: "Estimating dynamic panel data discrete choice models with fixed effects".

0305 Josep Pijoan-Mas: "Pricing risk in economies with heterogenous agents and incomplete markets".

0306 Gabriele Fiorentini, Enrique Sentana and Giorgio Calzolari: "On the validity of the Jarque-Bera normality test in conditionally heteroskedastic dynamic regression models".

0307 Samuel Bentolila and Juan F. Jimeno: "Spanish unemployment: The end of the wild ride?". 
0308 Rafael Repullo and Javier Suarez: "Loan pricing under Basel capital requirements".

0309 Matt Klaeffling and Victor Lopez Perez: "Inflation targets and the liquidity trap".

0310 Manuel Arellano: "Modelling optimal instrumental variables for dynamic panel data models".

0311 Josep Pijoan-Mas: "Precautionary savings or working longer hours?".

0312 Meritxell Albertí, Ángel León and Gerard Llobet: "Evaluation of a taxi sector reform: A real options approach".

0401 Andres Almazan, Javier Suarez and Sheridan Titman: "Stakeholders, transparency and capital structure".

0402 Antonio Diez de los Rios: "Exchange rate regimes, globalisation and the cost of capital in emerging markets".

0403 Juan J. Dolado and Vanessa Llorens: "Gender wage gaps by education in Spain: Glass floors vs. glass ceilings".

0404 Sascha O. Becker, Samuel Bentolila, Ana Fernandes and Andrea Ichino: "Job insecurity and children's emancipation".

0405 Claudio Michelacci and David Lopez-Salido: "Technology shocks and job flows".

0406 Samuel Bentolila, Claudio Michelacci and Javier Suarez: "Social contacts and occupational choice". 